\title{
Appraisal of Closed Active Surgical Drainage in High-Definition Torso Sculpting
}

\author{
SHERIF MAHER, M.D. \\ The Department of General Surgery, Fayoum University Hospital, Fayoum, Egypt
}

\begin{abstract}
Background: Lipoplasty techniques have evolved over the last century passing through several points of transmission and advancement from primitive curetting techniques to highdefinition sculpting; this path has been aided by the advent of the tumescent technique and VASER technology. VASER Assisted High Definition Liposculpting (VAHDL) has achieved an advanced three dimensional aesthetic results with minimal complication rate. Seroma formation is one of the most common complications that should be prevented to preserve sculpting results. There is nearly a consensus in literature about the active role of the surgical drainage in preventing this complication; however the type of this surgical drainage remains an issue of dispute that is still subjected to literature evaluation. Most of the previous studies have depended on the open drainage with many regards about the need for frequent dressing change.
\end{abstract}

Aim of Work: This study was designed to do an appraisal on the closed active drainage as a more convenient substitute for torso HDL patients.

Methods: From April 2016 to March 2019, a prospective case series study was carried out on 120 VAHDL patients presented with limited torso areas of fat accumulation. All patients were operated for the sculpting purpose by selecting those who presented with good muscle tone, BMI less than 35 , and without excessive skin laxity.

Results: The age of the patients ranged from 21 to 45 years; with female predominance (75 cases) representing $62.5 \%$ and BMI from 25 to 35 . Overall satisfactory result has been achieved in 105 patients representing $87.5 \%$ with higher satisfactory rate among male patients. Complication rate was $25.8 \%$ (31 cases) with unequal distribution among variety of possible lipoplasty complications.

Conclusion: Closed active drainage in spite of the problem of the clogged drain, still has the ability to achieve many advantages regarding effective prevention of seroma formation, elimination of the need for frequent dressing change, accurate drainage volume recording, less post-operative pain, ecchymosis, time needed for wearing compression garments, rapid recovery of post-operative edema and unmasking of sculpting aesthetics.

Key Words: Closed active drainage - High-definition sculpting - Torso sculpting - VAHDL.
INTRODUCTION

Lipoplasty techniques have evolved over the last century passing through several points of transmission and advancement from the different primitive curetting techniques to the recent highdefinition sculpting [1].

This long path has based mainly on the accurate knowledge of human anatomy, symmetry, proportions, different landmarks, and good understanding of how those landmarks display themselves and their appearance change with motion [2]; the other roles which were played by the advent of the tumescent technique and the development of new technologies have aided in lipoplasty transmission from a traditional primitive unrefined fat debulking, to a form of artistic sculpting [3].

In the recent years, high-definition lipoplasty has provided the aesthetic surgery an innovative solution to face the continuous escalated demands for the toned athletic appearance which can be achieved via exemplifying in a perfect and a harmonious manner the balanced anatomical definitions of the human body [4]; this solution has betted on the ability of revealing, modifying and creating controlled deformities [5].

To achieve those abilities and take the superiority over the traditional lipoplasty; high-definition lipoplasty was in a need to find a modern chisel giving the advantage of working in all the subcutaneous planes not only to debulk unrefined body contours but also to highlight the superficial musculature in a safe way to avoid the possibility of the final aesthetic compromise [6].

In pursuit of finding this modern surgical tool, Ultrasound-Assisted Lipoplasty (UAL) was advanced as a less traumatic procedure than the 
traditional suction-assisted methods; however the early reports have declared several complications related to burns, scarring, unintended contour deformities and regressed aesthetic results [7].

Third-generation ultrasound lipoplasty device: VASER (Vibration Amplification of Sound Energy at Resonance) has taken the place as the enabling technology to address the superficial and deep fat layers in an efficient and a safe manner through cavitation, expanding the clinical application of the differential lipoplasty in different body regions with fewer complications [8].

In 2003, a new concept of body contouring has been introduced and termed as "High Definition Liposculpture" (HDL) referring to an advanced sculpting approach that creates a slim athletic figure and selectively delineate the surface anatomy of the human body by proportional superficial and deep fat removal to highlight muscle groups [9].

HDL has been combined with the technological advancement of VASER which is currently considered as the gold standard for Liposculpting to overcome the technical challenge of superficial sculpting, facilitating refined contouring in delicate tissues, and achieving advanced three dimensional aesthetic results with minimal complication rate [10].

Recent studies have mentioned many advantages of VASER Assisted HDL (VAHDL) including shorter operative time than standard liposuction, less surgeon effort, more advantageous for tight, fibrous areas where increased blood loss would be expected, smaller incisions to access different zones, and selective disruption of relatively weak adipose tissue with sparing of the surroundings which can be translated to less bleeding, less bruising, and rapid recovery [11].

Those advanced aesthetic results of VAHDL cannot be realized without high level of training, experience, accurate knowledge and deep understanding of aesthetic ideals, how the superficial anatomy influences the external appearance and the aesthetic contributions made to the human body by the superficial and deep fat layers [12].

On the other hand, HDL as an advanced surgical technique which demands superficial plane sculpting to get the targeted aesthetic results and sometimes necessitates removal of large amounts of fats, has been surrounded by a many types of avoidable complications [13]; acute fluid collection due to the traumatic irritation of the tissues is one of those common complications which can occur especially with torso liposculpting and should be prevented to preserve sculpting results [14].

Hence, the agreed value of surgical drainage as one of the acute fluid collection preventing measures which guards the HDL results comes; however drainage system type remains an issue of dispute that is still subjected to literature evaluation [15].

\section{MATERIAL AND METHODS}

From April 2016 to March 2019, a prospective case series study was carried out on 120 VAHDL patients presented with limited torso areas of fat accumulation.

Our inclusion criteria has been meshed with the sculpting purpose by selecting those who presented with good muscle tone, BMI less than 35, and without excessive skin laxity.

Besides deep discussion and clear understanding of patients' wishes; pre-operative assessment of extra-abdominal torso fat distribution, contribution made by intra-abdominal one, muscular mass, tone, skin laxity, and waist contour was done.

Informed consent was obtained from all patients of the study who were good candidates for VAHDL according to their expectations and the physical examination and routine pre-operative laboratory tests were done.

Pre-operative framing of muscles and anatomical landmarks, marking of extra fat areas, determination of negative spaces and transition zones were done using different colour markers while the patient in the standing position Fig. (1).

All patients were operated under general anaesthesia starting with superficial and deep layers infiltration using the standard solution of $1,000 \mathrm{cc}$ normal saline, 1:100,000 epinephrine and lidocaine $20 \mathrm{cc}$ of $1 \%$ solution; half of the volume was infiltrated first into the deep layer followed by the other half into the superficial one.

Proceeding to the next step of emulsification after 10 minutes allows the vasoconstrictive effect to take place, starting with the superficial layer to be fully treated followed by the deep one rubbing our $2.9 \mathrm{~mm}$ or 3.7 probe against muscular layer with smooth probe movement and turned VASER system to the continuous mode at the power of 70$80 \%$; loss of resistance was our clinical endpoint 
and 1 minute per each $100 \mathrm{~mL}$ of infiltration was the duration limit of VASER use (30 minutes for 3 litters of solution).

Deep extraction from the deep fatty layer was done using $3.5 \mathrm{~mm}$ or $4 \mathrm{~mm}$ cannula, starting from the infraumbilical area proceeding to the flanks and supraumbilical region including the pectoral area in patients suffering from gynecomastia leaving a flap of $10 \mathrm{~mm}$ thickness in the anterior abdomen and $5 \mathrm{~mm}$ in the flanks.

By pinching the skin over a $3 \mathrm{~mm}$ cannula, superficial framing was done from different access incision sites Fig. (2) to frame the anterior abdominal wall anatomical landmarks in varied degrees taking into consideration patients gender and wishes; thin flaps were created exactly below the preoperative framing and following the real muscular curvatures to sculpt realistic and natural ridges or indentations.

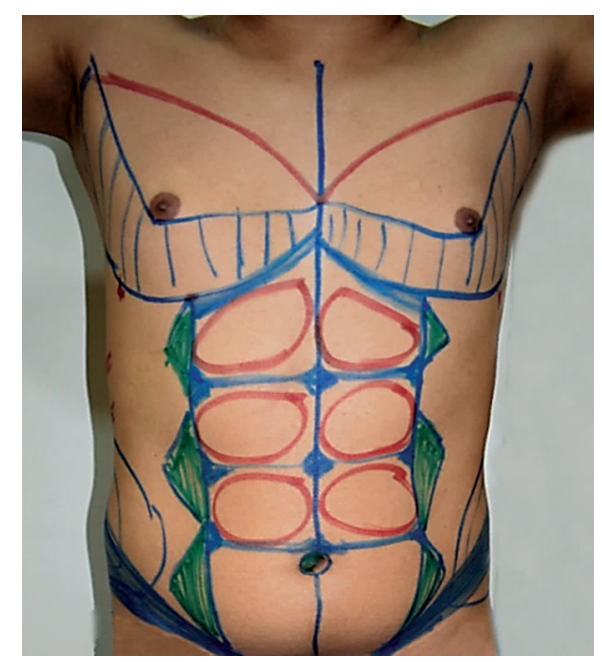

Fig. (1): Pre-operative farming and marking using different colour markers.

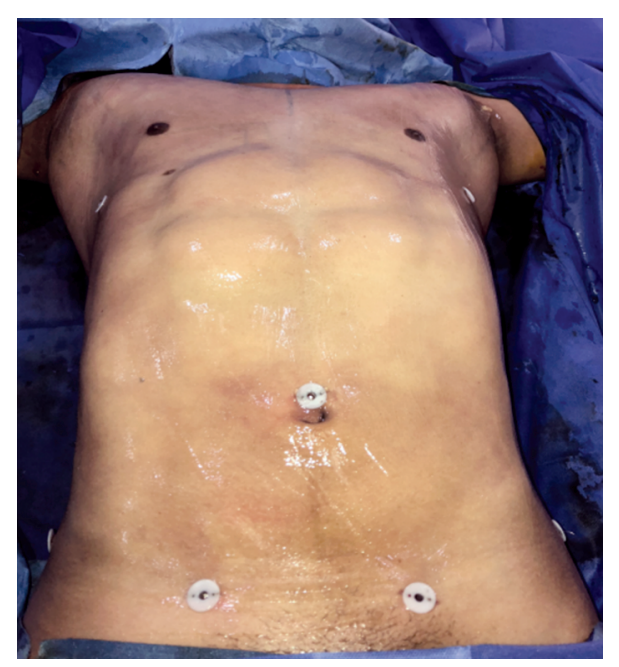

Fig. (2): Access incision sites.
In males, special attention was given for the need to define both recti and linea alba more prominently; three well defined horizontal inscriptions were done over the tendinous intersections of both recti in a direct manner sculpting from several access points using curved cannulas treating the superficial layer and later proceeding more deeply. Criss-crossing from different access sites was done to produce a natural tonal progression from the grooves to the convex surfaces.

VASER pulsed mode was used after suction at the power of $40-60 \%$ using a $2.9 \mathrm{~mm}$ probe to treat the delicate regions and other areas of skin laxity.

Superior and umbilical incisions were closed using subdermal sutures and closed suction drains (Surgivac) were left in the lower dependent incisions for 2 to 5 days (amount less than $50 \mathrm{cc}$ per day) together with the use of mild-compression garment for at least 4 weeks. Post-operative followup was scheduled at 1, 4, 8, 12 and 24 weeks for all patients.

\section{RESULTS}

The age of the patients ranged from 21 to 45 years; with female predominance $(75$ cases) representing $62.5 \%$ and BMI from 25 to 35 . Overall satisfactory result has been achieved in 105 patients representing $87.5 \%$ with higher satisfactory rate among male patients. Complication rate was $25.8 \%$ (31 cases) with unequal distribution among variety of possible lipoplasty complications (Table 1).

Table (1): Post-operative complications.

\begin{tabular}{lccc}
\hline Complication & Male & Female & Total \\
\hline Seroma & 1 & 1 & 2 \\
Edema \& induration & - & 2 & 2 \\
Pigmentation & 1 & 2 & 3 \\
Port-site burn & - & 1 & 1 \\
Distant burn & 1 & - & 1 \\
Sensory change & 2 & 3 & 5 \\
Contour irregularity & 2 & 4 & 6 \\
Skin laxity & 1 & 3 & 4 \\
Under correction & 3 & 2 & 5 \\
Overcorrection & 1 & 1 & 2 \\
Infection & - & - & - \\
Bleeding & - & - & - \\
Skin necrosis & & & - \\
Chronic edema & - & - & \\
\hline
\end{tabular}



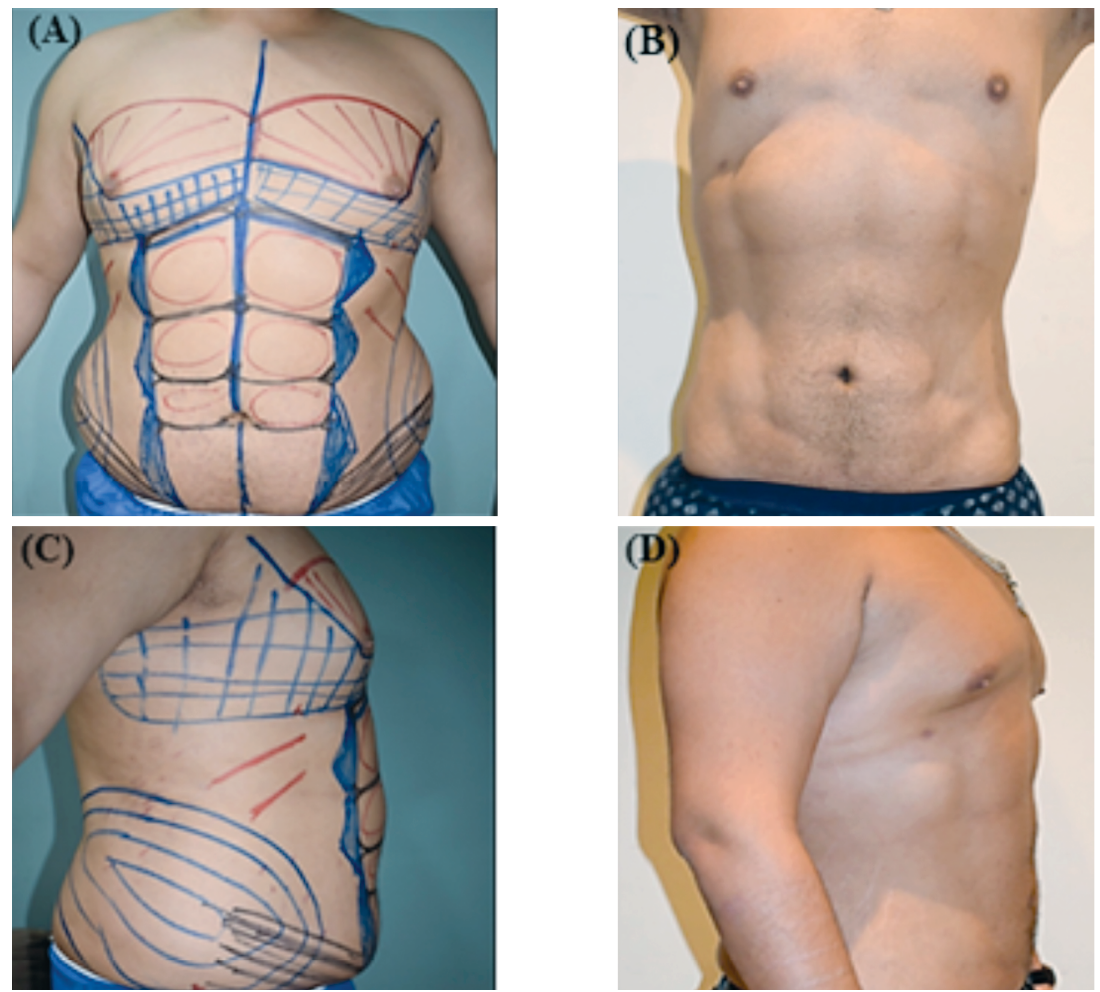

Fig. (3): (A) Pre-operative frontal view of male patient 37 years old, (B) Post-operative frontal view of the same patient after torso VAHDL, (C and D) Pre-operative and post-operative lateral views of the same patient.
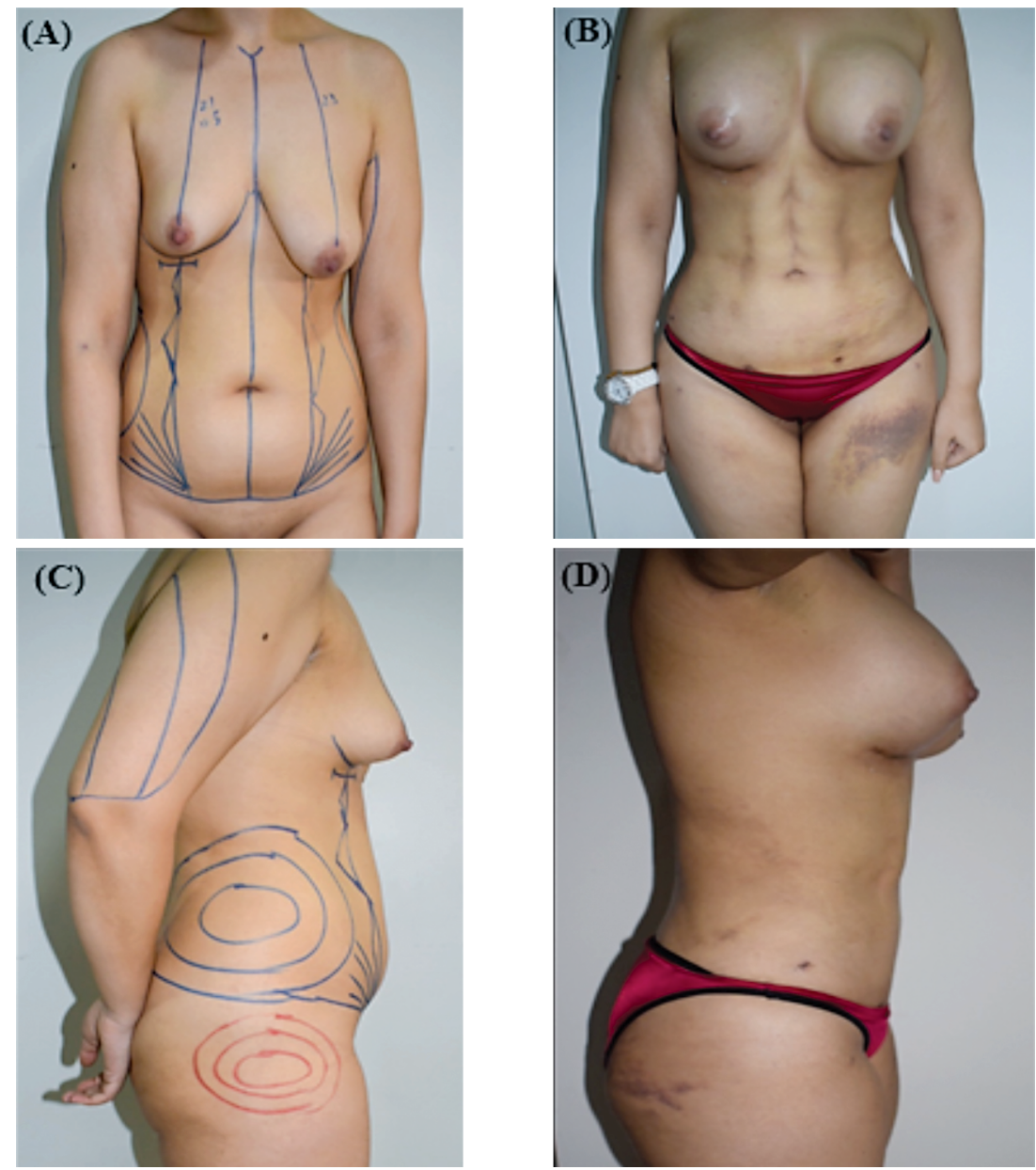

Fig. (4): (A,C) Pre-operative frontal and lateral views of female patient 35 years old, (B,D) Post-operative frontal and lateral views of the same patient after torso VAHDL and augmentation mammoplasty. 

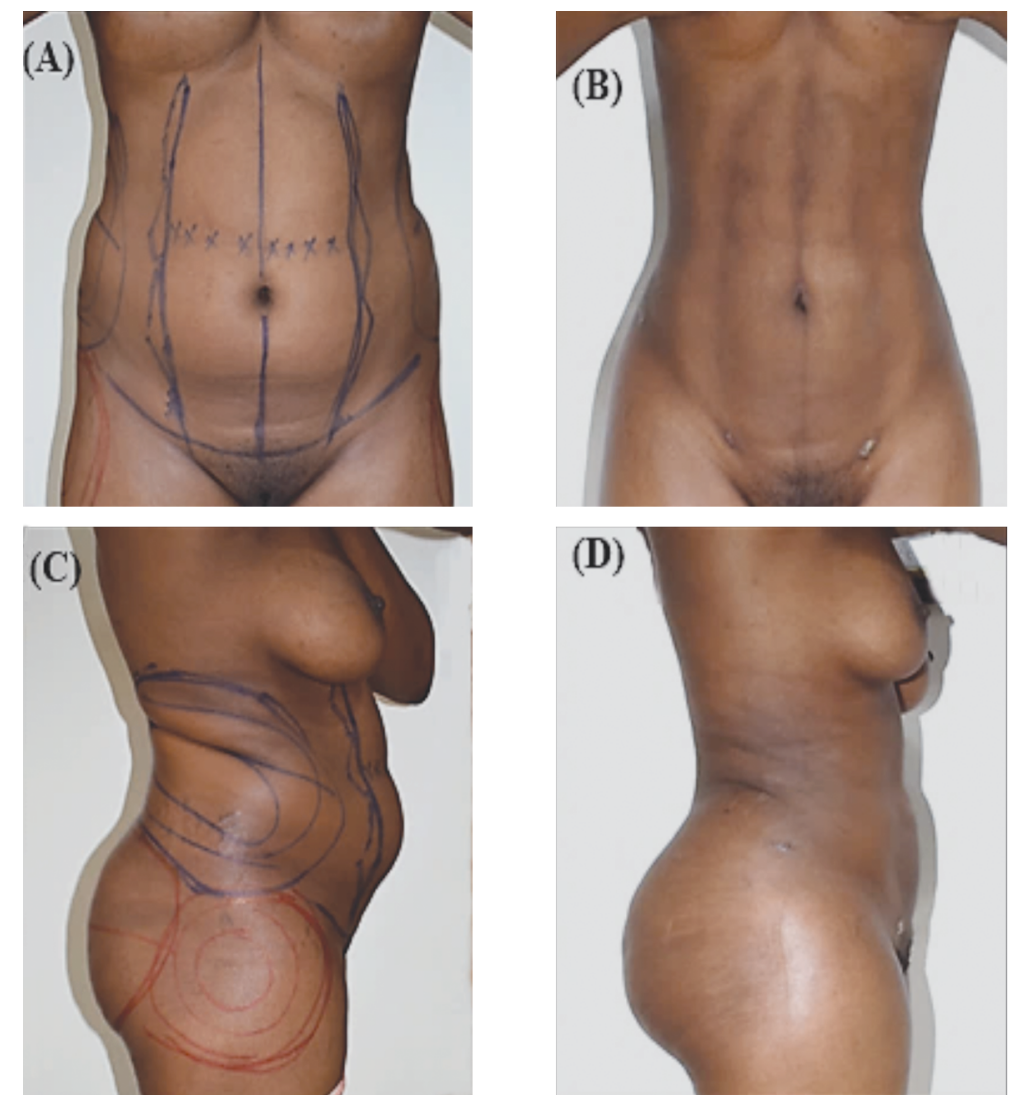

Fig. (5): (A) Pre-operative frontal view of female patient 32 years old, (B) Post-operative frontal view of the same patient after torso VAHDL and buttocks fat injection, $(\mathrm{C}, \mathrm{D})$ Pre-operative and post-operative lateral views of the same patient.
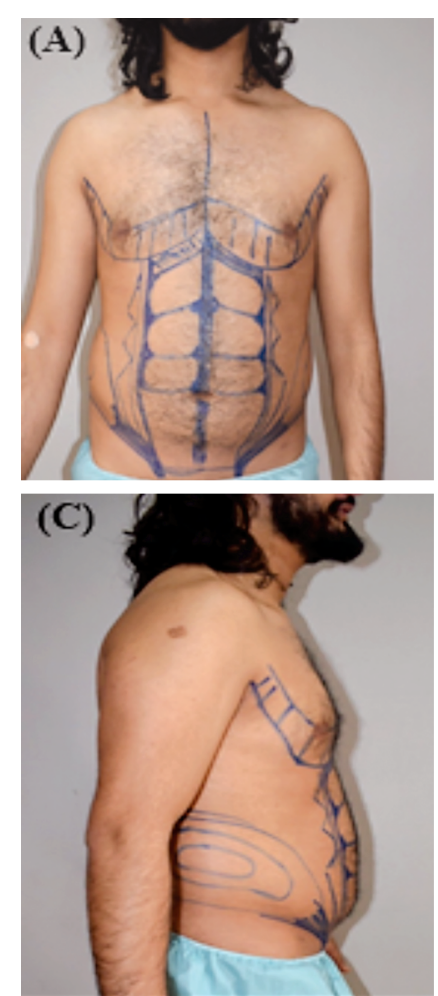
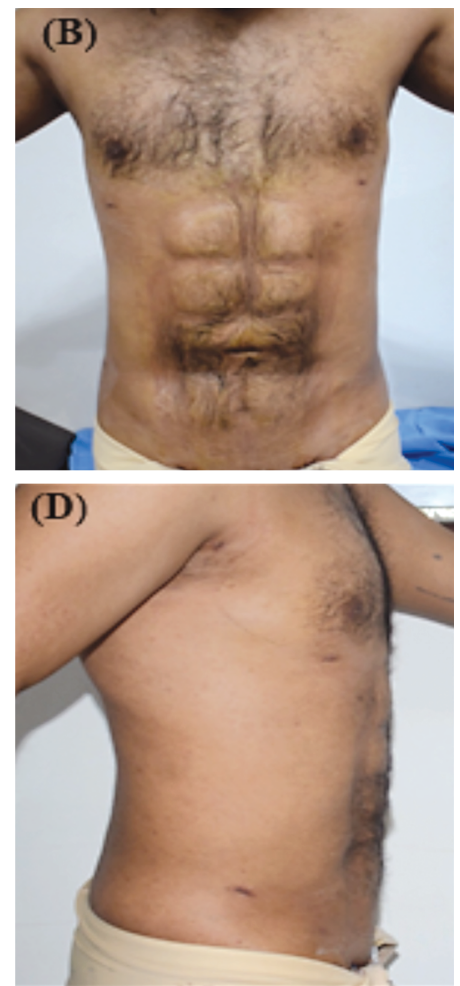

Fig. (6): (A) Pre-operative frontal view of male patient 40 years old, (B) Post-operative frontal view of the same patient after torso VAHDL, (C,D) Pre-operative and postoperative lateral views of the same patient. 
Closed drains have enabled the current study to accurately record both the range and average values of the drainage volumes over the first postoperative 5 days (Table 2), Chart (1) and the timing of drain removal among the patients (Table 3 ).

Table (2): Range and average drainage volumes.

\begin{tabular}{lccl}
\hline & Highest Vol & Lowest Vol & Mean Vol \\
\hline $1^{\text {st }}$ day & $450 \mathrm{cc}$ & $220 \mathrm{cc}$ & $310 \pm 36 \mathrm{cc}$ \\
$2^{\text {nd }}$ day & $180 \mathrm{cc}$ & $50 \mathrm{cc}$ & $110 \pm 21 \mathrm{cc}$ \\
$3^{\text {rd }}$ day & $130 \mathrm{cc}$ & $40 \mathrm{cc}$ & $65 \pm 16 \mathrm{cc}$ \\
$4^{\text {th }}$ day & $95 \mathrm{cc}$ & $30 \mathrm{cc}$ & $50 \pm 12 \mathrm{cc}$ \\
$5^{\text {th }}$ day & $60 \mathrm{cc}$ & $25 \mathrm{cc}$ & $35 \pm 5 \mathrm{cc}$ \\
\hline
\end{tabular}

Table (3): Timing of drain removal among patients.

\begin{tabular}{lc}
\hline Timing of removal & Patients percentage \\
\hline $2^{\text {nd }}$ day & $15 \%$ \\
$3^{\text {rd }}$ day & $45 \%$ \\
$4^{\text {th }}$ day & $30 \%$ \\
$5^{\text {th }}$ day & $10 \%$ \\
\hline
\end{tabular}

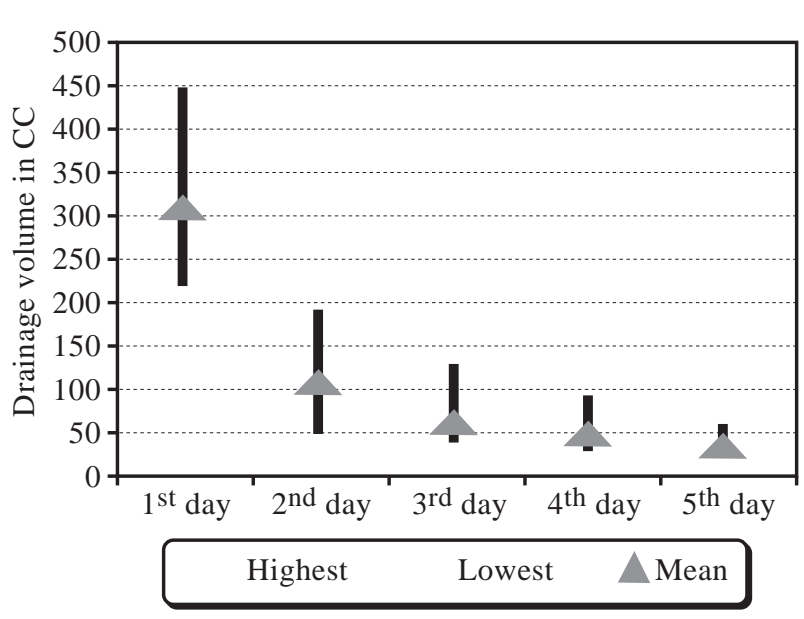

Chart (1): Range and average drainage volumes.

\section{Discussion}

High definition liposculpting employs advanced surgical techniques and a highly demanding step of extensive superficial sculpting which greatly affect the final aesthetic outcome [16]; these important points make HDL not a suitable procedure to be done by the inexperienced surgeons and should be done only by the surgeons who have prolific work in conventional lipoplasty [10].

HDL aesthetic outcome depends mainly on the well defining of the muscle groups and creating blended controlled irregularities which can be compromised by a variety of intraoperative and postoperative complications [17]; those complications can be avoided next to the surgeon high experience by the good planning, attention to details, skillful execution and well oriented postoperative care which optimizes the results of the work and helps to get the desired outcomes [18].

Seroma with its classic definition of postoperative inflammatory exudate collection in the subcutaneous tissues at the operative bed due to tissue trauma, burn, irritation or lymphatics breakdown represents one of the most encountered hindrances for good sculpting results [19]; absolutely this complication has an elevated rate with the obese patients, large amounts of fat debulking and extensive subcutaneous sculpting [20].

VAHDL has achieved high sculpting results and a dropped rate of seroma formation referring to the adopted lower BMI of the HDL which means less amounts of fat debulking and the valuable role of the VASER technology which reduces blood loss, tissue edema and promotes skin retraction [21].

There is a wide consensus about the important role of the surgical drainage and the continuous compression as effective methods that minimize the rate of this complication [22].

Most of the previous studies have depended on the dependent open drainage with wide variations in the reported rate of seroma formation; many regards were mentioned about the need for frequent dressing change with this type of surgical drainage [23]. Current study has betted on the closed active drainage (Surgivac) for the patients who have developed seroma at a rate of $1.6 \%$ ( 2 cases).

This complication was detected by the $5^{\text {th }}$ to the $7^{\text {th }}$ post-operative day usually in the lower abdomen and outer aspects of the thighs. Diagnosis was done by the clinical examination and all were managed successfully within 2 to 3 weeks by the repeated needle aspirations under sterile precautions followed by adequate compression; there are no resistant or chronic cases.

Many advantages, closed active drainage has achieved in the current study; it eliminates the dead space, prevents fluid accumulation, enables accurate volume recording, eliminates the need for frequent dressing change, achieved less postoperative pain, ecchymosis, time needed for wearing compression garments and gives more advanced results than the other studies that adopt open drainage regarding seroma formation and rapid recovery of post-operative edema and unmasking of sculpting aesthetics. 
On the otherhand the problem of the clogged drains in few numbers of the patients has faced and the risk of tissue injury from the suction force remains a theoretical possibility.

Edema, induration and ecchymosis can be anticipated as transient reactions of the human tissues to the trauma produced by the cannula which usually respond to the conservative measures within 4 to 8 weeks with complete return to the normal appearance after 12 weeks [24].

In the current study, two patients representing $1.6 \%$ have developed post-operative edema and induration within the first week that were managed successfully with optimum compression.

A thorough pre-operative evaluation of the coagulation profile, liver and platelets functions, pre-operative stoppage of the antiplatelet medications, usage of adrenaline in the tumescent solution, blunt tipped small cannulae together with the postoperative adequate compression have prevented hematoma development in the patients as one of the possible post-operative complications.

Many authors have reported infection rate less than $1 \%$ that usually occurs as a direct consequence of the secondary bacterial infection of the postoperative hematoma or uncontrolled diabetes [24].

This study has adopted besides the basic principles of infection control and sterilization, routine pre-operative blood sugar measurement for all patients, strict perioperative glycemic control for diabetic patients, perioperative smoking stoppage, and post-operative prophylactic antibiotics; those measures have nullify the infection rate in our patients.

The complication of the skin hyperpigmentation has been reported in several studies with wide variation in the incidence due to the hemosiderin deposition from ecchymosis [25]; three cases in the study representing $2.5 \%$ have developed this complication, they have been managed successfully with conservative measures.

Skin necrosis is another possible complication that occurs as a direct consequence of the subdermal vascular plexus damage which has an increased incidence in chronic smokers, with sharp cannulae usage and with aggressive liposuction [19]; this type of complication has not occurred in our patients.

Five patients representing $4.1 \%$ have suffered from transient hypoesthesia which represents one of the very common neurologic sequels of liposuction and liposculpture operations.

Other complications are the port-site and distant burns; both types were superficial and have faced us in two patients which have been managed conservatively. Secondary procedures were required for 3 patients to correct contour irregularities, residual skin laxity and localized residual fat deposits.

\section{Conclusion:}

High definition liposculpting is a highly demanding aesthetic surgery that can achieve advanced results only by the highly experienced surgeons.

It has provided the aesthetic surgery an innovative solution to face the continuous escalated demands for the toned athletic appearance.

It has been combined with the technological advancement of VASER to overcome the technical challenge of superficial sculpting with minimal complication rate.

One of those avoidable common complications that surround Torso HDL is the acute fluid collection; it should be prevented to preserve sculpting results.

There is an agreed value about the role of the surgical drainage in preventing the acute fluid collection and preserving the sculpting results.

Most of the previous studies have depended on the dependent open drainage with many regards about the need for frequent dressing change with this type of surgical drainage.

Current study has done an appraisal on the closed active drainage as a more convenient substitute for torso HDL patients.

Closed active drainage in spite of the problem of the clogged drain, still has the ability to achieve many advantages regarding effective prevention of seroma formation, elimination of the frequent need for dressing change, enables accurate drainage volume recording, less postoperative pain, ecchymosis, time needed for wearing compression garments, rapid recovery of post-operative edema and unmasking of sculpting aesthetics.

\section{REFERENCES}

1- Flynn T., Coleman W., Field L., Klein J. and Hanke W.: History of Liposuction. Dermatologic Surgery, 26 (6): pp. 515-20, 2000. 
2- Hoyos A. and Prendergast P. ed.: Muscular and Surface Anatomy. In: High Definition Body Sculpting: Art and Advanced Lipoplasty Techniques, $1^{\text {st }}$ ed. Berlin: Springer, pp. 19-21, 2014.

3- Prendergast P.: Liposculpture of the Abdomen in an OfficeBased Practice. In: M. Shiffman and A. Di Giuseppe, ed., Body Contouring: Art, Science, and Clinical Practice, $1^{\text {st }}$ ed. Berlin: Springer, pp. 219-37, 2011.

4- Fisher G.: Liposculpture: The "Correct" History of Liposuction. Part I. The Journal of Dermatologic Surgery and Oncology, 16 (12): pp. 1087-9, 1990.

5- Jewell M.: Clinical application of VASER-assisted lipoplasty: A pilot clinical study. Aesthetic Surgery Journal, 22 (2): pp. 131-46, 2002.

6- Cimino W.: Ultrasound-Assisted Lipoplasty: Basic Physics, Tissue Interactions, and Related Results/Complications. In: P. Prendergast and M. Shiffman, ed., Aesthetic Medicine Art and Techniques, $1^{\text {st }}$ ed. Berlin: Springer, pp. 51928, 2012.

7- Troilius C.: Ultrasound-assisted lipoplasty: Is it really safe? Aesthetic Plastic Surgery, 23 (5): pp. 307-11, 1999.

8- Shridharani S., Broyles J. and Matarasso A.: Liposuction devices: Technology update. Medical Devices: Evidence and Research, Jul. (7): pp. 241-51, 2014.

9- Oaxaca C.: High-Definition Liposculpture. In: N. Serdev, ed., Body Contouring and Sculpting, $1^{\text {st }}$ ed. Rijeka: IntechOpen, pp. 65-79, 2016.

10- Hoyos A. and Millard J.: VASER-assisted high-definition liposculpture. Aesthetic Surgery Journal, 27 (6): pp. 594604, 2007.

11- Bellini E., Grieco M. and Raposio E.: A journey through liposuction and liposculture: Review. Annals of Medicine and Surgery, Dec., (24): pp. 53-60, 2017.

12- Nicolaides K.: History. In: S. Parashar, L. Toledo and A. Govila, ed., Art of Abdominal Contouring: Advanced Liposuction, $1^{\text {st }}$ ed. New Delhi: Jaypee Brothers, pp. 13, 2016.

13- Pitanguy I.: Evaluation of Body Contouring Surgery Today: A 30-Year Perspective. Plastic \& Reconstructive Surgery, 105 (4): pp. 1499-514, 2000.

14- Shiffman M.: Prevention and treatment of liposuction complications. In: M. Shiffman and A. Di Giuseppe, ed., Liposuction: Principles and Practice, $1^{\text {st }}$ ed. New York: Springer, pp. 333-41, 2006.

15- Janis J., Khansa L. and Khansa I.: Strategies for Postoperative Seroma Prevention. Plastic and Reconstructive Surgery, 138 (1), pp. 240-52, 2016.

16- Soto J., Aguilar H. and Barajas-Gamboa J.: High Definition Liposuction: A Challenge for a Perfect Body Contouring. In: N. Serdev, ed., Body Contouring and Sculpting, $1^{\text {st }}$ ed. Rijeka: IntechOpen, pp. 65-79, 2016.

17- Kim Y., Cha S., Naidu S. and Hwang W.: Analysis of Post-operative Complications for Superficial Liposuction: A Review of 2398 Cases. Plastic and Reconstructive Surgery, 127 (2): pp. 863-71, 2011.

18- Danilla S., Babaitis R., Jara R., Quispe D., Andrades P., Erazo C., Albornoz C. and Sepulveda S.: High-Definition Liposculpture: What are the Complications and How to Manage Them?. Aesthetic Plastic Surgery, 43 (1): pp. 1$8,2019$.

19- Dixit V. and Wagh M.: Unfavourable outcomes of liposuction and their management. Indian Journal of Plastic Surgery, 46 (2): pp. 377-92, 2013.

20- Kim Y., Cha S., Naidu S. and Hwang W.: Analysis of Post-operative Complications for Superficial Liposuction: A Review of 2398 Cases. Plastic and Reconstructive Surgery, 127 (2): pp. 863-71, 2011.

21- Kim J. and Stevenson T.: Abdominoplasty, Liposuction of the Flanks, and Obesity: Analyzing Risk Factors for Seroma Formation. Plastic and Reconstructive Surgery, 117 (3): pp. 773-9, 2006.

22- Klein J.: Post-Tumescent Liposuction Care. Dermatologic Clinics, 17 (4): pp. 881-9, 1999.

23- Stebbins W., Hanke C. and Petersen J.: Ultrasound-guided drainage of a seroma following tumescent liposuction. Dermatologic Therapy, 24 (1): pp. 121-4, 2011.

24- Toledo L. and Mauad R.: Complications of Body Sculpture: Prevention and Treatment. Clinics in Plastic Surgery, 33 (1): pp. 1-11, 2006.

25- Mateu L. and Hernandez J.: Cutaneous Hyperpigmentation Caused by Liposuction. Aesthetic Plastic Surgery, 21 (4): pp. 230-2, 1997. 